\title{
Characteristics of pigeons' spatial working memory in an open-field task
}

\author{
MARCIA L. SPETCH and WERNER K. HONIG \\ Dalhousie University, Halifax, Nova Scotia, Canada
}

\begin{abstract}
Although pigeons seem to require special training before they will display accurate spatial working memory in radial-arm mazes, they readily show accurate working memory for recently visited feeder locations in an open-field analog of the radial maze. In this task, pigeons forage among sites located on the floor of an open room, with no constraints on the path they take between sites. Experiment 1 suggested that pigeons' working memory for recently visited sites is facilitated if they are permitted to develop a stable reference memory "map" of the location of the sites with respect to landmarks in the room: Pigeons for which the landmarks remained constant from day to day displayed more accurate working memory than did pigeons for which the landmarks were rearranged between daily trials. The second experiment investigated the durability of pigeons' working memory, using a forced-choice procedure. Accuracy remained high for retention intervals of up to $32 \mathrm{~min}$, but dropped significantly with a 2 -h delay.
\end{abstract}

Rats and other rodent species readily display working memory for recently visited spatial locations on the radialarm-maze task (see, e.g., Olton, 1978; Wilkie \& Slobin, 1983). In contrast, pigeons tend to perform poorly on this memory task (Bond, Cook, \& Lamb, 1981) unless first given special, lengthy training (Roberts \& Van Veldhuizen, 1985). One possible reason why pigeons might seem "unprepared" to display their spatial working memory abilities in the radial-maze task is that the labyrinthine structure of the maze might be constraining or disrupting for a species that normally feeds in open areas (Roberts \& Van Veldhuizen, 1985). The forced detour inherent in the radial-maze task, of always returning to the center area between choices, might add a further disruption for birds that normally should be able to fly over obstacles and thereby take more direct paths between food sites (Spetch \& Edwards, 1986).

On the premise that efficient spatial memory performance might emerge more readily in laboratory settings that more closely resemble the natural feeding environment (e.g., Pike, 1981), Spetch and Edwards (1986) tested pigeons' spatial working memory in two open-field analogues of the radial-arm maze. The first consisted of a number of elevated food sites attached to the walls of an open room; the pigeons flew to perches mounted at these sites to obtain the food. The pigeons chose among these sites with accuracy levels that were above chance, but the apparatus was problematic because the pigeons often perched at the sites for long periods of time between

This research was supported by Natural Sciences and Engineering Research Council of Canada operating grants (U0301, M. Spetch; A0102, W. Honig). The assistance of Elizabeth Buckle and Loralee MacLean is gratefully acknowledged. Dallas Treit made many valuable comments on an earlier version of the manuscript. Reprint requests should be addressed to Marcia L. Spetch, who is now at the Department of Psychology, University of Alberta, Edmonton, AB T6G 2E9, Canada. choices. The second open-field-maze analogue was free of this perching problem, and also generated much higher levels of accuracy. In this, second task, food sites (milk cartons of different colors and patterns) were placed on the floor of the room, and the pigeons could walk freely around the room choosing among these until they located the food hidden inside each site. The 10 pigeons tested readily achieved high levels of choice accuracy, and test trials indicated that their choices were not controlled by cues emanating from the food. The pigeons also did not appear to rely on the distinct visual features of the food sites to perform accurately. Finally, although some birds developed consistent response patterns, computer simulations suggested that these response patterns did not wholly account for their high levels of accuracy.

These results suggested that the open-field setting should be well suited to studying the characteristics of spatial memory in pigeons. The present experiments therefore employed this paradigm to examine two aspects of these memory characteristics. The first experiment was concerned with the relationship between working memory and reference memory (see Honig, 1978). Specifically, to what extent is a stable reference-memory "map" of the spatial relationships between stimuli necessary or important for accurate working-memory performance (see Honig, 1987)? The second experiment examined the temporal persistence of pigeons' working memory for spatial locations over various retention intervals.

\section{EXPERIMENT 1}

In this experiment, we asked whether pigeons' ability to remember which sites they had visited within the current trial (i.e., working memory) was affected by the constancy of spatial landmarks across trials. If the working memory consisted of a "list" of isolated cues that each identified a particular visited site, it might not be affected 
by the stability of landmarks between trials. For example, the pigeon might remember that it had been to the site beside the rock, the site closest to the window, and the site beneath the sunset picture. As long as these landmarks were not moved within the trial, the pigeon could use them to avoid returning to these sites. It might not matter that the locations of some landmarks varied between trials.

On the other hand, a memory that entails marking off recently visited places on a "cognitive map" (i.e., on a reference memory of spatial relationships in the arena; see, e.g., Roberts, 1984; Suzuki, Augerinos, \& Black, 1980; Tolman, 1948) might depend critically on the stability of landmark cues across trials. Constant rearrangement of the landmarks would prevent the birds from forming a stable representation of spatial relationships between the landmarks and the feeding sites, between the landmarks and static features of the room, and between the landmarks themselves. To the extent that these relationships constituted an important part of the cognitive map, this manipulation should disrupt a working memory based on this map.

Some analyses of rats' radial-arm-maze performance have seemed to support a list-like conception of working memory (Olton, 1978). For example, analysis of errors did not indicate a tendency to generalize among spatially adjacent arms, which suggested that rats treated each arm independently of the others (Olton \& Samuelson, 1976). However, subsequent evidence has challenged this view. Suzuki et al. (1980) tested rats in an enclosed maze that contained distinct extramaze stimuli at the end of each arm. In their first experiment, they found that rats trained with these stimuli present performed better than rats trained without these stimuli. In their second experiment, they forced rats to three of the arms and then confined them in the center area while the stimuli and the respective baits were rotated or rearranged. The rats' ability to subsequently locate the baited arms was disrupted by rearrangement of the stimuli but not by rotation, which suggested to Suzuki et al. that the places were defined by the configuration of the stimuli rather than by individual stimuli in isolation. This finding suggests that the withintrial constancy of spatial relationships is important for working memory in the radial-arm maze.

An experiment by Mazmanian and Roberts (1983) further argued for a map-based spatial working memory. They found that restricting the scope of the rats' view at the end of arms (while still permitting a view of distinct cues at the ends of these arms), severely disrupted working-memory performance in a four-arm maze. This manipulation would not be expected to produce such a dramatic effect on a working memory based on a list of isolated cues, but would clearly impede memory based on a map of relationships between cues.

The spatial configuration of stimuli also seems to be important in rats' reference memories in radial-arm mazes. Cheng and Gallistel (1984) tested rats in a fourarm maze housed inside a rectangular enclosure. The arms pointed toward distinct visual landmarks and contained different amounts of food. Choice behavior was unaffected by rotation of the landmarks (and respective baits) by $180^{\circ}$, but was completely disrupted by an affine transformation (rotated $90^{\circ}$, which altered the distance between pairs of landmarks)'or a reflection transformation (interchanging pairs of landmarks so that the left-right configuration is reversed).

There is mixed evidence concerning the extent to which the arrangement of landmark features is important for spatial reference memory in open-field settings. Cheng (1986) tested rats' working and reference memory for the location of hidden food in a rectangular open field with distinct visual features and olfactory cues in the corners. He found that the rats relied primarily on geometric relationships between the goal and the overall shape of the environment. Use of the nongeometric information appeared to be subordinate to the use of the shape of the environment, and the rats did not seem to use the overall arrangement of the nongeometric stimuli.

Spatial relationships among landmarks located within an open field may, however, be important in gerbils' reference memories of a goal location (Collet, Cartwright, \& Smith, 1986). Collet et al. suggested that the gerbils plan trajectories based on distances and bearings between individual landmarks and the goal, but use featural properties of the landmarks and geometric relationships between them to match landmarks seen while planning a trajectory to those held in memory.

Recent studies of hamsters' exploratory reactions to spatial rearrangements of familiar objects in an open field also suggest that their reference memories may include both the geometrical configuration of the object array (Thinus-Blanc et al., 1987) and topological relationships between the objects (Poucet, Chapuis, Durup, \& ThinusBlanc, 1986).

In spite of evidence suggesting that spatial configurations can be important for both working memory and reference memory, there appears to be only limited evidence to suggest that spatial working-memory performance is affected by the between-trial constancy of spatial relationships. Kraemer, Gilbert, and Innis (1983) trained rats on a radial maze with intramaze cues as the only salient features available on some days. Betweentrial rearrangement of these intramaze cues significantly retarded the acquisition of accurate choice behavior on these trials, but did not prevent it from ultimately developing. This suggested that a stable reference memory of cue configurations may facilitate, but not be essential for, accurate radial-arm-maze performance by rats.

Roberts and Van Veldhuizen (1985) examined the effect of both within-trial and between-trial rearrangements of intramaze cues on pigeons' working-memory performance in the radial-arm maze. Within-trial rearrangement of intramaze cues produced a significant, but not a complete, disruption of working-memory accuracy. Rearrangement of the intramaze cues between trials produced a significant increase in reference-memory errors (choice 
of arms that were never baited) and a nonsignificant increase in working-memory errors (reentry into one of the baited arms). Thus, the evidence to date indicates a facilitating, but nonessential, role for the between-trial stability of spatial cues in working memory.

The present experiment examined the effect of continuous between-trial rearrangements of spatial landmarks on pigeons' working-memory performance in the open-field task of Spetch and Edwards (1986). A number of movable landmarks were added to the spatial arena: four surface landmarks and three wall decorations. For one group of pigeons, the locations of these landmarks remained constant from day to day. For a second group of pigeons, the locations of these landmarks were constant within each working-memory trial but were continually rearranged between the daily trials. This manipulation would leave the spatial relationships between the food sites and the static features of the room intact, but would prevent the birds from forming a stable representation of relationships between the food sites and individual landmarks, or between the array of landmarks and static features of the room. Accuracy in avoiding sites already visited on the current trial was compared in the two groups during initial acquisition with a free-choice procedure and then, during subsequent tests, with a forced-choice procedure.

\section{Method}

\section{Subjects}

The subjects were 9 adult White King pigeons and 1 adult Silver King pigeon (218). Six of the subjects (216, 218, 3241, 1043, 217, and 4830 ) had previously served briefly in a spatial memory experiment, which took place in a different room and entailed physically different food sites from those used in the present experiment. The remaining 4 subjects had extensive histories in operant conditioning chambers but no previous experience in spatial memory tasks. All birds were maintained at about $85 \%$ of their free-feeding weights, and were housed in individual wire-mesh cages with free access to water and grit.

\section{Apparatus}

The open-field arena consisted of a rectangular, $2.4 \times 2.3 \times 2.4 \mathrm{~m}$ test room with a door on one wall and two windows on the other (see Figure 1). One window was opaque, but the other contained one-way glass through which the test room could be viewed from a separate observation room. The four inside walls of the test room were painted white, but contained some distinctive features (e.g, sockets, doorstop, light switch, the windows, the door, etc.) that could serve as spatial landmarks. In addition to these static landmarks, the room contained four surface landmarks (a rock, a long stick, a block of wood, and an inverted plastic bowl), and three distinct wall landmarks (photographs of a swan, a flower, and a sunset, mounted on backgrounds of different sizes, colors, and shapes). The locations of the eight food sites and the seven movable landmarks can be seen in Figure 1. Illumination was provided by a single overhead light bulb.

The eight food sites were each constructed of 2-liter milk cartons that differed in color and patterning. The cartons were modified so that their tops were open with a semicircular entrance hole on the front side. An additional strip of cardboard (of the same visual design as the carton) was attached to the top to provide extra height and "flaps" to border the entrance (see Figure 1). The cartons were filled with grit to $10 \mathrm{~cm}$ below the entrance, and they were baited by placing kernels of com on the grit against the front wall of the carton, beneath the entrance. Each carton was placed on a wooden platform. Attached to the front of each platform was a ramp that served as a "walkway" to the carton entrance; strips of wood glued onto the ramp served as rungs.

These food sites were a modification of the feeders used by Spetch and Edwards (1986). The ramps were added to facilitate scoring of choice behavior. With the original feeders, the operational definition of a choice as insertion of the beak into the opening was occasionally difficult to score, particularly from certain vantage points or for birds that moved very rapidly around the arena. The ramp arrangement allowed for a more easily scored choice, operationally defined as a step onto the ramp. The flaps bordering the open-
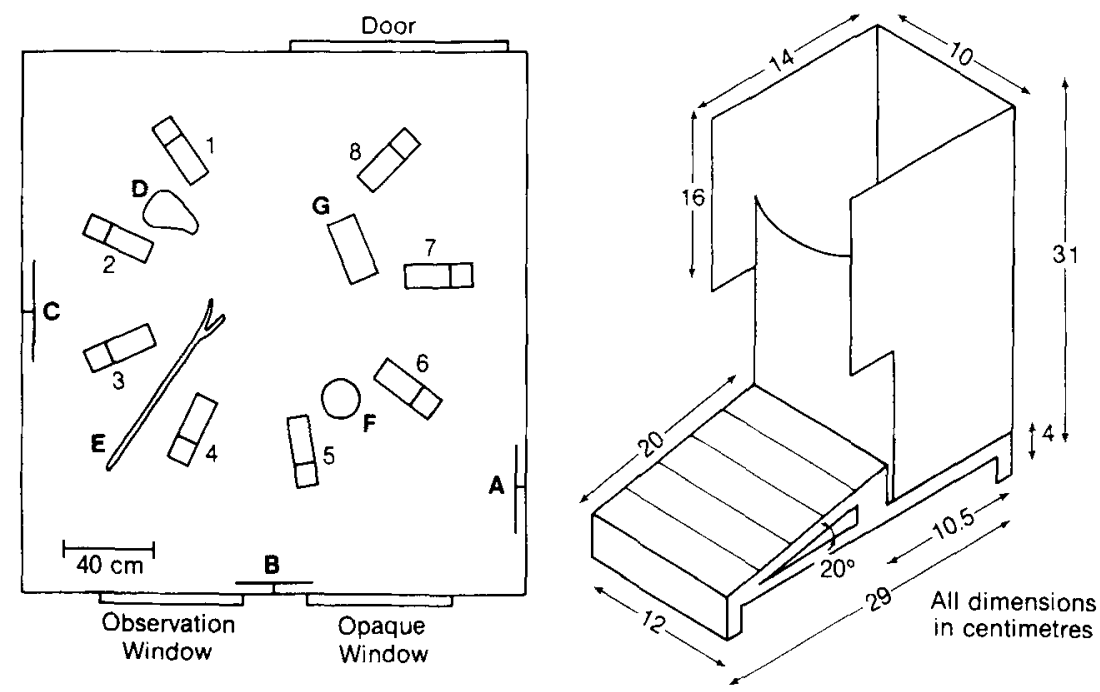

Figure 1. Left panel: Top view diagram of the spatial arrangement of the food sites (1-8), the movable surface landmarks (D-G), and the movable wall landmarks (A-C). Right panel: Diagram of the food sites and the ramps on which they were placed. 
ing ensured that the pigeons had access to the entrance only from the ramp. A second potential advantage of the ramp arrangement was that it made choice responses a little more effortful.

\section{Procedure}

Pretraining. Prior to the first pretraining session, the $10 \mathrm{sub}-$ jects were assigned to two groups (Constant and Variable), matched in terms of prior experimental histories. Each bird then received three phases of pretraining. In Phase 1, the pigeon was placed in the room with only one food site in place (Site 1). The carton and the ramp leading up to it were baited with corn. Phase 1 continued until the bird ate all the corn from the carton within a 30-min session. During Phase 2, four food sites were in place (Sites 1, 5, 6, and 8), and corn was place inside each carton and on the top rung of each ramp. During this phase, the three wall landmarks were also introduced. If the bird ate from the four cartons within a session, it was advanced to Phase 3. During this, third phase, all eight cartons, the four surface landmarks, and the wall landmarks were in place, and corn was placed inside each carton only. Pretraining was complete when the bird ate from all eight cartons within the 30 -min session. The number of sessions required for pretraining are shown for each subject in Table 1. Subject 216 was dropped from the experiment because of problematic behavior that emerged during pretraining. (This bird repeatedly flew to the top of each food site and unsuccessfully attempted to eat the food while perching on the rim. This sometimes resulted in the bird's knocking over the site; on other occasions, the bird toppled into the site.)

Free-choice training. During this phase, the birds in each group received 10 free-choice working-memory trials. At the beginning of each trial, all eight sites were baited with five kernels of corn. The pigeon was placed in the center of the room with the light out. Once the experimenter arrived at the observation window, the testroom light was turned on and the pigeon was free to choose among the sites until it located and consumed all the food. The experimenter recorded when and in what order each site was chosen, with choices operationally defined as stepping with both feet onto the ramp. This definition appeared satisfactory because, with the exception of the one discarded subject, none of the birds were ever observed to locate or eat the food hidden inside the carton without first walking up the ramp, and only very occasionally did a bird step onto the ramp and then fail to eat food that was inside the carton. Once all sites had been visited, the light was turned out and the bird was removed from the room to end the trial.

For birds in Group Constant, the four surface landmarks and the four wall landmarks were always in the same place in the room on each trial. With reference to the locations indicated in Figure 1,

Table 1

Number of Pretraining Sessions Received by Each Subject in Experiment 1

\begin{tabular}{lcccc}
\hline Subject & Phase 1 & Phase 2 & Phase 3 & Total \\
\hline & \multicolumn{3}{c}{ Constant Group } & \\
218 & 2 & 3 & 2 & 7 \\
216 & 2 & 1 & $*$ & $*$ \\
3241 & 1 & 1 & 1 & 3 \\
219 & 1 & 1 & 1 & 3 \\
440 & 1 & 2 & 1 & 4 \\
& & Variable Group & & \\
217 & 2 & 1 & 1 & 4 \\
4830 & 2 & 1 & 1 & 4 \\
220 & 1 & 2 & 1 & 4 \\
221 & 1 & 1 & 1 & 3 \\
1043 & 1 & 1 & 2 & 4 \\
\hline
\end{tabular}

*Dropped from the experiment; see text for details. the rock was at location $D$, the stick at $G$, the bowl at $F$, and the block of wood at $E$. The flower picture was at wall location $C$, the duck picture at $B$, and the sunset picture at $A$. The same general floor and wall locations were used for Group Variable, but the particular landmark that was placed at each location varied randomly from day to day. As a result, the relationship between the landmarks and any particular sites or any specific features of the room varied randomly across trials. However, within each trial, the configuration of the landmarks remained constant.

Forced-choice testing. During the 10 trials of this phase, a forcedchoice procedure was used that would prevent the birds from using a response strategy to achieve high levels of choice accuracy. During the first part of the trial, only four, randomly selected sites were available; the food cartons from the other sites were removed from the room (leaving just the ramps in place). Once the pigeon had eaten from each of these four sites, the light was turned out and the pigeon was removed from the room. The four cartons that had been removed earlier were then baited with food and returned to their appropriate sites, and the bird was returned to the center of the room. After a retention interval of $2 \mathrm{~min}$ (from the time the light was turned out), the light was turned on to begin the second part of the trial. Here, the bird had free choice of all eight cartons, but only the four cartons that had been missing from the room during the first part of the trial contained food. The bird was allowed to choose until it located all four baited sites.

As in the previous phase, the locations of the seven landmarks were constant both within and between the 10 forced-choice trials for birds in Group Constant. For birds in Group Variable, the landmarks were randomly rearranged between trials. However, their locations were constant within each trial.

Throughout this experiment, the subjects received one trial per day for 5 days per week.

Analysis of choice accuracy. During the free-choice phase, accuracy was determined by the number of different sites chosen among the first eight choices made. During forced-choice tests, two measures of accuracy were employed. The primary measure used was the number of correct (i.e., baited) sites visited during the first four choices that followed the retention interval. Random sampling among the eight alternatives during the postretention test would generate an average of 1.66 correct in the first four choices (Roberts, 1984). This score is subject to two types of errors: Visiting sites chosen prior to the retention interval (preretention errors), and repeated choice of a site during the postretention test (postretention errors). The second measure of forced-choice accuracy we employed excluded the postretention repeat errors. This measure, which we refer to as retention accuracy, used the number correct in the first four sites chosen after the retention interval. Chance-level accuracy for this measure is 2.0 correct.

\section{RESULTS}

\section{Free-Choice Performance}

Pigeons in both the Constant and the Variable groups performed accurately during the 10 free-choice trials. The mean number of different sites chosen among the first eight choices for the two groups is shown for the two trial blocks in Figure 2. An analysis of variance on these data revealed no significant effect of group $[F(1,7)=3.27$, $p>.1]$ or of trial block $[F(1,7)=.64, p>.1]$ and no significant interaction $[F(1,7)=.21, p>.1]$.

Although these results revealed no difference between pigeons in the two groups, this result is difficult to interpret, because some birds displayed consistent response 
patterns that may have at least partially contributed to their accurate choice performance.

\section{Forced-Choice Accuracy}

Figure 3 shows the mean number correct among the pigeons' first four choices during the two blocks of forcedchoice test trials. Accuracy was higher for birds in the Constant group than for birds in the Variable group during both blocks of trials. A two-way analysis of variance confirmed that there was a significant effect of groups $[F(1,7)=13.13, p<.01]$ but not of trial block $[F(1,7)$ $=1.83, p>.1]$; there was no significant interaction between groups and trial block $[F(1,7)=.03, p>.1]$.

Although there was a significant difference in accuracy between the two groups, it should be noted that the accuracy levels of both groups were higher than that expected by random sampling among the eight alternatives ( 1.66 correct). The difference between the obtained values and this chance-level estimate was significant for both the Constant group $[t(3)=10.6, p<.01]$ and the Variable group $[t(4)=10.4, p<.01]$.

Since most of the errors made were of the preretention type, exclusion of the postretention repeat errors did not change the significant findings. Retention accuracy was significantly higher for the Constant group $(M=3.28)$ than for the Variable group $(M=2.74)[t(7)=2.72, p<.05]$, and these scores were significantly higher than the level expected by chance ( 2.0 correct) for both groups [Constant, $t(3)=7.72, p<.01$; Variable, $t(4)=6.35$, $p<.01]$.

Other than the difference in accuracy levels, no obvious behavioral differences between the groups were observed. For example, the time taken to make four choices

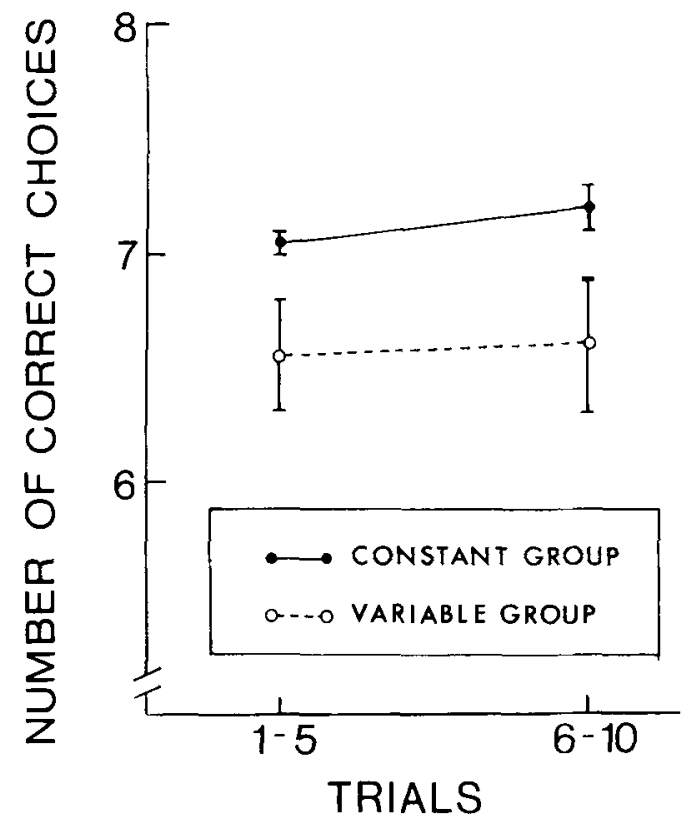

Figure 2. Mean (and SEM) number correct in the first eight choices for birds in the Constant group (solid circles) and Variable group (open circles) during the first five and the last five trials of freechoice training in Experiment 1.

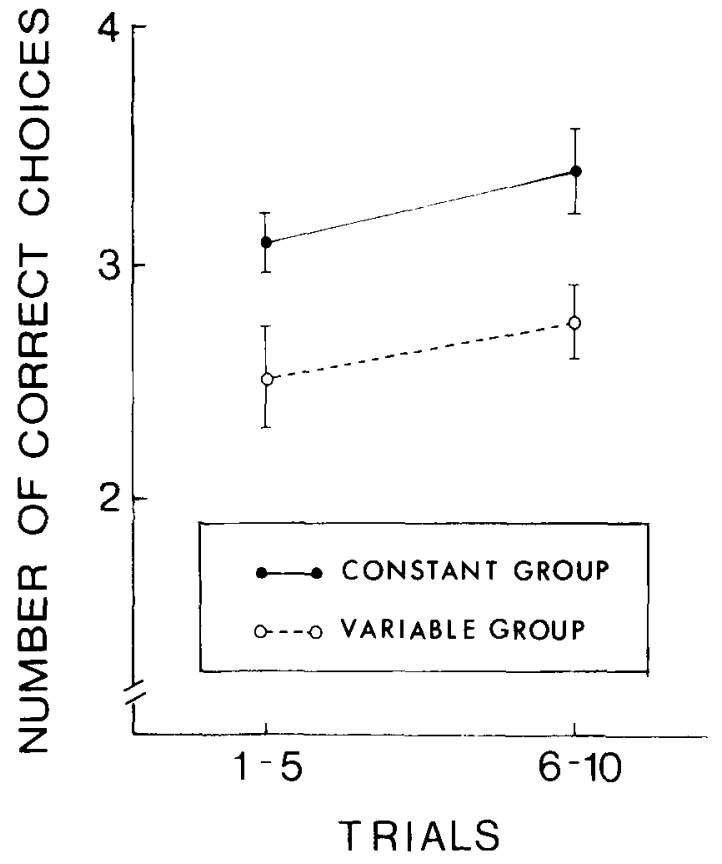

Figure 3. Mean (and SEM) number correct in the first four choices after the retention interval for birds in the Constant group (solid circles) and Variable group (open circles). Data are shown for the first five and the last five trials of forced-choice training in Experiment 1.

during the retention part of the trial was equivalent for the two groups [Constant group, $M=75 \mathrm{sec}$, and Variable group, $M=71 \mathrm{sec} ; t(7)=.18, p>.1]$. Thus, there was no indication that the birds in the Variable group were distressed or disrupted, in a general sense, by the rearrangements of the landmark cues.

\section{DISCUSSION}

The present results suggest that the between-trial stability of spatial landmark configurations is important for pigeons' spatial working-memory performance. Pigeons for which the landmarks were rearranged between trials performed less accurately in forced-choice tests than did pigeons exposed to a constant configuration of the landmarks. The finding that accuracy did not differ significantly between the groups during free-choice testing (in which strategies other than memory could be employed to perform accurately), together with the failure to observe any other behavioral differences between birds in the two groups, suggests that the rearrangement of the landmarks affected memory processes rather than performance in general. It appears that pigeons are better able to remember which sites they have visited on the current trial if they are permitted to form a stable referencememory "map" of where the site is with respect to spatial landmarks. However, the rearrangements of the landmarks between trials by no means completely impaired working memory, because pigeons in the Variable group still performed well above chance level on the forcedchoice tests. 
In general, these results seem consistent with those obtained with rats in the radial-arm maze, in that they suggest that the ability to form a cognitive map of spatial relationships facilitates, but is not essential for, workingmemory performance (Kraemer et al., 1983). However, the present results may differ from those obtained by Kraemer et al. in that, in their study, the effect of the cue rearrangements was observed during acquisition. In the present study, the landmark rearrangements did not have a significant effect on accuracy during free-choice acquisition, but did affect forced-choice performance.

\section{EXPERIMENT 2}

One characteristic of pigeons' spatial working memory that remains in question is its durability over a retention interval. Roberts and Van Veldhuizen (1985) exposed pigeons to a variable retention interval following four forced choices on the radial-arm maze. The pigeons showed a significant decline in accuracy over delays of up to $6 \mathrm{~min}$. Spetch and Edwards (1986) similarly tested pigeons' retention following four forced choices in the flight apparatus, and also observed a significant decline in accuracy over a retention interval of $5 \mathrm{~min}$. This forgetting over delays of only a few minutes stands in contrast with results obtained with rats in the radial-arm maze. For example, Beatty and Shavalia (1980) found that rats showed no significant forgetting of four forced choices over a period of as long as $4 \mathrm{~h}$. Similarly, in an openfield analogue of the radial-arm maze, Clark's nutcrackers were recently found to show no significant forgetting of four forced choices over retention intervals of up to $6 \mathrm{~h}$ (Balda \& Kamil, 1988). Thus, the ability to remember four locations in working memory over long retention intervals may reveal a difference between these species and pigeons.

To date, however, the durability of pigeons' spatial working memory for four visited locations has been assessed only in situations that may be less than ideal. The radial-arm maze does not seem optimal because pigeons require lengthy training to perform well in that apparatus, and the flight task was found to generate performance problems. The present experiment therefore sought to examine the effect of retention intervals on pigeons' performance within a paradigm that generated high levels of baseline accuracy without extended training.

\section{METHOD}

\section{Subjects and Apparatus}

The 4 subjects from the Constant group of Experiment 1 were used in this experiment; the apparatus was also the same. Throughout this experiment, all landmarks remained constant, and in the same locations used for this group in Experiment 1.

\section{Procedure}

Retention interval testing began directly after completion of Experiment 1 . Two series of retention tests were conducted. In the first series, $102-\mathrm{min}, 108-\mathrm{min}$, and 1032 -min retention intervals were used, for a total of 30 trials. In the second series, $102-\mathrm{min}$ and 10 2-h retention intervals were used, for a total of 20 trials. During each series, the order of the retention intervals varied within blocks of trials.

A forced-choice procedure was used throughout this experiment. At the beginning of each trial, four randomly selected sites were available. Once the pigeon consumed the food from each of these, it was removed from the room and placed in a holding cage in an adjacent room for the duration of the retention interval. When this interval had elapsed, the bird was placed back into the room with all eight cartons in place. Only those not visited prior to the retention interval contained food. The pigeon was permitted free choice among the eight cartons until it located and consumed all of the food.

Trials were conducted once a day for 4 or 5 days a week. Recording and analysis of choice behavior was conducted as in Experiment 1 .

\section{RESULTS}

The left panel of Figure 4 shows the number correct among the first four choices for each subject, averaged over the first five trials (top) and over the second five trials (bottom), at each retention interval tested during Series 1. The connected points represent the mean scores for the 4 subjects. The right panel of the figure shows the results for the two retention intervals tested in Series 2.

During Series 1, the 32-min delay appeared to have some disruptive effect during the first block of trials, but accuracy remained high across all three retention intervals during the second block of trials. A two-way analysis of variance on the Series 1 data revealed no significant effect of the retention interval $[F(2,6)=3.27$, $p>.1]$ or of trial block $[F(1,3)=6.54, p>.05]$ and no significant interaction $[F(2,6)=1.98, p>.1]$.

In contrast, there was a dramatic reduction in accuracy with the 2-h delay during both blocks of trials in Series 2 . The effect of retention interval during this series was highly significant $[F(1,3)=67.0, p<.01]$. The effect of trial blocks did not reach significance $[F(1,3)=6.1$, $p>.05]$, and there was no significant interaction between retention interval and trial blocks $[F(1,3)=.22$, $p>.1]$.

Accuracy levels at all delays tested were significantly $(p<.05)$ above the chance level expected on the basis of random sampling among the eight alternatives (1.66 correct). However, postretention repeat errors were very rare (i.e., they formed fewer than $5 \%$ of the errors). Therefore, a better indication of retention over the delay is provided by comparing retention accuracy scores (shown in Table 2) with the level expected by chance for this measure ( 2.0 correct). Averaged across the two trial blocks, retention accuracy was significantly $(p<.05)$ above the 2.0 chance level for each retention interval in Series 1, and for the 2-min delay in Series 2. However, retention accuracy was not significantly above this chance level after the 2 -h delay $[t(3)=1.98, p>.1]$.

\section{DISCUSSION}

The results of this experiment suggest a more favorable estimate of the temporal persistence of pigeons' work- 
SERIES 1
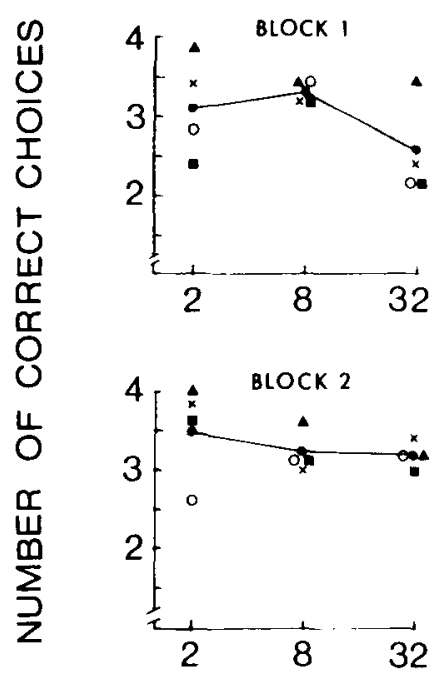

SERIES 2
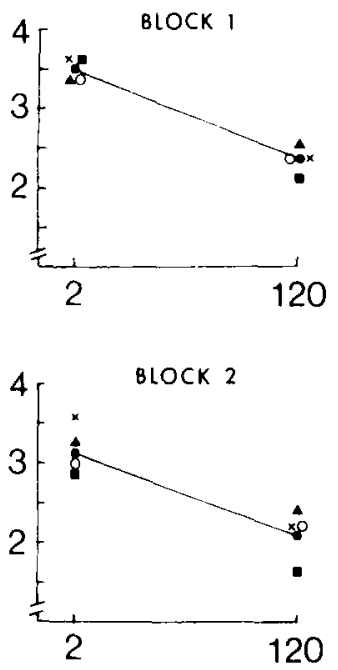

RETENTION INTERVAL (MIN)

\begin{abstract}
Figure 4. Number of correct choices out of four as a function of the retention interval for the 4 pigeons in Experiment 2. The left panel shows the results of the first series of retention-interval tests; the right panel shows the results of the second series. The top graph in each panel shows data from the first five trials at each retention interval; the bottom panel shows data from the last five trials at each retention interval. The points joined by lines indicate the mean of the 4 subjects; the unconnected symbols represent data for the individual pigeons.
\end{abstract}

ing memory for four spatial locations than do the previous findings of Roberts and Van Veldhuizen (1985) or Spetch and Edwards (1986). Clearly, the setting in which pigeons are tested can be a major determinant of their memory performance. The difference between these results and those obtained by Spetch and Edwards (1986) is not surprising, given that the flight apparatus they used was found to produce performance problems and that the baseline levels of accuracy at the shortest retention interval were quite low. However, a significant reduction in accuracy over retention intervals of only 6 min was also observed in the Roberts and Van Veldhuizen (1985) study, in which baseline levels of accuracy were high. There are several possible reasons why the pigeons in the present experiment were able to tolerate longer retention intervals without significant memory loss. One is that the openfield apparatus seems to encourage the use of spatial working memory in pigeons, perhaps because it resembles their natural feeding habitats (Spetch \& Edwards, 1986). In this open setting, pigeons do not require the extensive training that they seem to need in radial-arm mazes before they will display accurate working memory (Roberts \& Van Veldhuizen, 1985); perhaps pigeons are also more likely to persist in using memory despite substantial delays in this type of setting. The difference could also be related to procedural differences between the experiments. For example, in the present study, pigeons were removed and retained in a separate room during the retention interval, whereas in Roberts and Van Veldhuizen's study, the pigeons remained in the center of the maze. Perhaps removal from the test environment helps to isolate and protect the memory from retroactive interference. Finally, retention in the present study may have been facilitated by the richness of the cues available. Although Robert and Van Veldhuizen's study provided the birds with both intramaze and extramaze cues, our experiment may have provided even more sources of information because there were carton-specific cues (intramaze), global room location cues, and the specific local landmarks added to the room.

Although pigeons displayed excellent retention abilities in the present study relative to previous findings, it should be noted that substantial forgetting did occur over a 2-h delay; in fact, after the 2-h delay, retention accuracy was not significantly above chance level. This is still considerably shorter than the delays over which rats (Beatty \& Shavalia, 1980) and Clark's nutcrackers (Balda \& Kamil, 1988) seem able to remember four spatial locations without loss.

\section{GENERAL DISCUSSION}

In Experiment 1, accuracy during forced-choice testing was significantly lower for the group of pigeons that had different arrangements of spatial landmarks on every trial than for the group that had the same landmark 
Table 2

Retention Accuracy (Number Correct Among First Four Sites Chosen) Following Each Retention Interval Tested in Experiment 2

\begin{tabular}{|c|c|c|c|c|c|c|c|}
\hline \multirow[b]{2}{*}{ Series } & \multirow[b]{2}{*}{ Delay } & \multirow[b]{2}{*}{ Trials } & \multicolumn{4}{|c|}{ Subjects } & \multirow[b]{2}{*}{ Mean } \\
\hline & & & 218 & 3241 & 219 & 440 & \\
\hline \multirow[t]{3}{*}{1} & $2 \mathrm{~min}$ & $\begin{array}{l}1-5 \\
6-10\end{array}$ & $\begin{array}{l}3.4 \\
3.8\end{array}$ & $\begin{array}{l}3.8 \\
4.0\end{array}$ & $\begin{array}{l}2.8 \\
2.6\end{array}$ & $\begin{array}{l}2.8 \\
3.8\end{array}$ & $\begin{array}{l}3.2 \\
3.55\end{array}$ \\
\hline & $8 \mathrm{~min}$ & $\begin{array}{l}1-5 \\
6-10\end{array}$ & $\begin{array}{l}3.2 \\
3.0\end{array}$ & $\begin{array}{l}3.6 \\
3.6\end{array}$ & $\begin{array}{l}3.4 \\
3.2\end{array}$ & $\begin{array}{l}3.2 \\
3.2\end{array}$ & $\begin{array}{l}3.35 \\
3.25\end{array}$ \\
\hline & $32 \mathrm{~min}$ & $\begin{array}{l}1-5 \\
6-10\end{array}$ & $\begin{array}{l}2.4 \\
3.2\end{array}$ & $\begin{array}{l}3.4 \\
3.2\end{array}$ & $\begin{array}{l}2.2 \\
3.2\end{array}$ & $\begin{array}{l}2.2 \\
3.0\end{array}$ & $\begin{array}{l}2.55 \\
3.2\end{array}$ \\
\hline \multirow[t]{2}{*}{2} & $2 \min$ & $\begin{array}{l}1-5 \\
6-10\end{array}$ & $\begin{array}{l}3.6 \\
3.6\end{array}$ & $\begin{array}{l}3.4 \\
3.4\end{array}$ & $\begin{array}{l}3.4 \\
3.0\end{array}$ & $\begin{array}{l}3.6 \\
2.8\end{array}$ & $\begin{array}{l}3.5 \\
3.2\end{array}$ \\
\hline & $2 \mathrm{~h}$ & $\begin{array}{l}1-5 \\
6-10\end{array}$ & $\begin{array}{l}2.4 \\
2.2\end{array}$ & $\begin{array}{l}2.6 \\
2.4\end{array}$ & $\begin{array}{l}2.4 \\
2.2\end{array}$ & $\begin{array}{l}2.2 \\
1.6\end{array}$ & $\begin{array}{l}2.4 \\
2.1\end{array}$ \\
\hline
\end{tabular}

arrangements on every trial. This suggested that the between-trial stability of spatial relationships affected the pigeons' working memory for which locations they had visited on the current trial. This result seems to indicate an interactive relationship between working and reference memory, one in which the accuracy of working memory is affected by the stability of the reference memory. More specifically, this result seems consistent with views of a working memory that records visited places in terms of locations on a cognitive map: rearrangement of spatial landmarks between the daily trials would inhibit the formation of a stable cognitive map in reference memory.

The disruption of working memory by the between-trial rearrangements of the landmarks was by no means complete, however. Although birds in the Variable group performed less accurately than did birds exposed to constant rearrangements of the landmarks, they still performed well above chance level during forced-choice testing. It remains to be determined whether this represents some independence of working memory from reference memory, or the fact that some aspects of the cognitive map remained constant across trials for both groups. For example, the relationship between the food sites and the geometric features of the room would not have been affected by the landmark rearrangements. If these are as important for the spatial reference memories of pigeons as they seem to be for rats (Cheng, 1986), then the lack of a complete disruption by landmark rearrangements alone would not be surprising. At any rate, the present findings seem consistent with the results of a similar manipulation in the radial-maze apparatus with rats: rearrangement of intramaze cues between trials seemed to retard but not prevent the use of an accurate working memory by rats (Kraemer, et al., 1983). This parallel appears to support the suggestion by Roberts and Van Veldhuizen (1985) that many properties of spatial memory seem similar for pigeons and rats.

The high levels of accuracy on the forced-choice procedure shown by birds in the Constant group of Experiment 1 suggested that the present apparatus would be ideal for examining the temporal persistence of pigeons' spatial working memory. In Experiment 2, therefore, we varied the interval between forced and free choices. The pigeons showed accurate working-memory performance without significant loss after retention intervals of up to $32 \mathrm{~min}$, but showed a dramatic drop in accuracy after a retention interval of $2 \mathrm{~h}$. These results provide a higher estimate of the retention interval over which pigeons can accurately remember four forced choices than those provided by two previous experiments on this question (Roberts \& Van Veldhuizen, 1985; Spetch \& Edwards, 1986). This could reflect the use of the open-field setting, the richness of the cues available, removal of the birds during the retention interval, or all three of these factors. On the other hand, our results are inconsistent with suggestions (Balda \& Kamil, in press; Roberts \& Van Veldhuizen, 1985) that the temporal persistence of spatial working memory in an eight-goal task may offer a potential distinction between species: our pigeons showed a substantial decrement in accuracy within a 2-h retention interval, whereas rats have been reported to show no significant memory loss over retention intervals of $4 \mathrm{~h}$ in similar forced-choice procedures (Beatty $\&$ Shavalia, 1980). Clark's nutcrackers, a species known to display excellent spatial memory in natural settings, also showed no significant memory loss in a forced-choice procedure for retention intervals of up to $6 \mathrm{~h}$ (Balda \& Kamil, 1988). Although comparisons between species and different experimental settings are always problematic, there does, indeed, seem to be a difference in working-memory abilities between these species and pigeons. However, the magnitude of this difference seems less impressive in light of the present results.

It is interesting to speculate on reasons why the formation of a stable reference-memory map might facilitate the accuracy of working memory. One possibility is that it allows the animal to take full advantage of the many redundant relevant cues available in most spatial workingmemory tasks (Olton, 1978). Cognitive mapping may serve to define each food-site location in terms of a number of distinct features. In the present setting, the sites could be defined in terms of their exact locations in the room, their locations with respect to the surface or wall landmarks, their locations with respect to one another, 
or their visual features. In the radial-arm-maze apparatus, there often appears to be some redundancy in the cues that control working-memory performance for both rats (e.g., Kraemer et al., 1983) and pigeons (Roberts \& Van Veldhuizen, 1985). Spetch and Edwards (1988) recently found that pigeons readily incorporate redundant sources of spatial information into their reference memory of goal locations within the open-field setting. With such a multiple-feature cognitive map, it is possible that the pigeon may need to attend to only one of these features during a visit to a site in order to activate a representation of that site in terms of its many defining features. If the single attended feature were then to be forgotten from working memory, the visited site could still be identified on the basis of other associatively activated features. In essence, there could be facilitation of working memory by within-compound associations between the various redundant relevant cues that define each site. Some of these associations would be disrupted by continual rearrangement of the spatial landmarks between trials.

\section{REFERENCES}

BALDA, R. P., \&AMIL, A. C. (1988). The spatial memory of Clark's nutcrackers (Nucifraga columbiana) in an analogue of the radial arm maze. Animal Learning \& Behavior, 16, 116-122.

BeatTy, W. W., \& Shavalia, D. A. (1980). Spatial memory in rats: Time course of working memory and effects of anesthetics. Behavioral \& Neural Biology, 28, 454-462.

Bond, A. B., Cook, R. G., \& LAMB, R. M. (1981). Spatial memory and performance of rats and pigeons in the radial-arm maze. Animal Learning \& Behavior, 9, 575-580.

ChENG, K. (1986). A purely geometric module in the rat's spatial representation. Cognition, 23, 149-178.

Cheng, K., \& Gallistel, C. R. (1984). Testing the geometric power of an animal's spatial representation. In H. L. Roitblat, T. G. Bever, \& H. S. Terrace (Eds.), Animal cognition (pp. 409-423). Hillsdale, NJ: Erlbaum

Collett, T. S., Cartwright, B. S., \& Smith, B. A. (1986). Landmark learning and visuo-spatial memories in gerbils. Journal of Comparative Physiology A., 158, 835-851.

HoNIG, W. K. (1978). Studies of working memory in the pigeon. In S. H. Hulse, H. Fowler, \& W. K. Honig (Eds.), Cognitive processes in animal behavior (pp. 211-248). Hillsdale, NJ: Erlbaum.
HoNiG, W. K. (1987). Local cues and distal arrays in the control of spatial behavior. In P. Ellen \& C. Thinus-Blanc (Eds.), Cognitive processes and spatial orientation in animal and man: Vol. l. Experimental animal psychology and ethology. Dordrecht: Martinus Nijhoff.

Kraemer, P. J., Gilbert, M. E., \& InNis, N. K. (1983). The influence of cue type and configuration upon radial-arm maze performance in the rat. Animal Learning \& Behavior, 11, 373-380.

MAZMANIAN, D. S., \& RoberTs, W. A. (1983). Spatial memory in rats under restricted viewing conditions. Learning \& Motivation, 14, 123-139.

Olton, D. S. (1978). Characteristics of spatial memory. In S. H. Hulse, H. Fowler, \& W. K. Honig (Eds.), Cognitive processes in animal behavior (pp. 341-373). Hillsdale, NJ: Erlbaum.

Olton, D. S., \& SAMUelson, R. J. (1976). Remembrance of places passed: Spatial memory in rats. Journal of Experimental Psychology: Animal Behavior Processes, 2, 97-116.

PIKE, G. H. (1981). Hummingbird foraging on artificial inflorescences. Behavior Analysis Letters, 1, 11-15.

Poucet, B., Chapuis, N., Durup, M., \& Thinus-Blanc, C. (1986). A study of exploratory behavior as an index of spatial knowledge in hamsters. Animal Learning \& Behavior, 14, 93-100.

ROBERTs, W. A. (1984). Some issues in animal spatial memory. In H. L. Roitblat, T. G. Bever, \& H. S. Terrace (Eds.), Animal cognition (pp. 425-443). Hillsdale, NJ: Erlbaum.

Roberts, W. A., \& VAN Veldhuizen, N. (1985). Spatial memory in pigeons on the radial arm maze. Journal of Experimental Psychol ogy: Animal Behavior Processes, 11, 241-259.

SPETCH, M. L., \& EDWARDS, C. A. (1986). Spatial memory in pigeons (Columba livia) in an open-field feeding environment. Joumal of Comparative Psychology, 100, 266-278.

SPETCH, M. L., \& Edwards, C. A. (1988). Pigeons' (Columba livia) use of global and local cues for spatial memory. Animal Behaviour, 36, 293-295.

Suzuki, S., Augerinos, G., \& Black, A. (1980). Stimulus control of spatial behavior on the eight-arm radial maze in rats. Learning \& Motivation, 11, 1-18.

Thinus-Blanc, C., Bouzouba, L., Chaix, K., Chapuis, N., Durup, M., \& PouCET, B. (1987). A study of spatial parameters encoded during exploration in hamsters. Journal of Experimental Psychology: Animal Behavior Processes, 13, 418-427.

Tolman, E. C. (1948). Cognitive maps in rats and men. Psychological Review, 55, 189-208.

WiLKIE, D. M., \& SLobin, P. (1983). Gerbils in space: Performance on the 17-arm radial maze. Journal of the Experimental Analysis of Behavior, 40, 301-312.

(Manuscript received May 15, 1987; revision accepted for publication December 8,1987 .) 